\title{
ChemComm
}

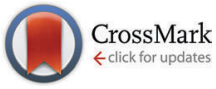

Cite this: Chem. Commun., 2016, 52,331

Received 14th September 2015, Accepted 20th October 2015

DOI: $10.1039 / \mathrm{c5cc07664a}$

www.rsc.org/chemcomm

\section{Design and synthesis of a new chromophore, 2-(4-nitrophenyl)benzofuran, for two-photon uncaging using near-IR light $\dagger$}

\author{
Naomitsu Komori, ${ }^{a}$ Satish Jakkampudi, ${ }^{\text {ab }}$ Ryusei Motoishi, ${ }^{a}$ Manabu Abe, ${ }^{* a b c}$ \\ Kenji Kamada, ${ }^{* d}$ Ko Furukawa, ${ }^{e}$ Claudine Katan ${ }^{*}{ }^{\dagger}$ Wakako Sawada, ${ }^{9}$ \\ Noriko Takahashi, ${ }^{9}$ Haruo Kasai, ${ }^{\text {bg }}$ Bing Xue ${ }^{\text {bh }}$ and Takayoshi Kobayashi ${ }^{\text {bh }}$
}

\begin{abstract}
A new chromophore, 2-(4-nitrophenyl)benzofuran (NPBF), was designed for two-photon (TP) uncaging using near-IR light. The TP absorption (TPA) cross-sections of the newly designed NPBF chromophore were determined to be $18 \mathrm{GM}$ at $720 \mathrm{~nm}$ and $54 \mathrm{GM}$ at $740 \mathrm{~nm}$ in DMSO. The TP uncaging reaction of a caged benzoate with the NPBF chromophore quantitatively produced benzoic acid with an efficiency $\left(\delta_{\mathrm{u}}\right)$ of $\sim 5.0 \mathrm{GM}$ at $740 \mathrm{~nm}$. The TP fragmentation of an EGTA unit was observed with $\delta_{\mathrm{u}}=16 \mathrm{GM}$. This behavior makes the new chromophore a promising TP photoremovable protecting group for physiological studies.
\end{abstract}

Caged compounds ${ }^{1}$ have attracted considerable interest in physiological studies, e.g. in neuroscience, due to their many applications. $^{2-5}$ These compounds, in which biologically active molecules are inactivated by photoremovable protecting groups (PPGs), ${ }^{6}$ can uncage (=release) bioactive molecules upon photolysis (Fig. 1). ${ }^{4}$ Spatial and temporal control of the uncaging process allows detailed investigation of the role of bioactive molecules in vivo.

Two-photon absorption (TPA) by near-IR irradiation of light (approximately 700-1300 $\mathrm{nm}$ ) has been increasingly used for photolysis in biological studies because most living tissues

\footnotetext{
${ }^{a}$ Department of Chemistry, Graduate School of Science, Hiroshima University, 1-3-1 Kagamiyama, Higashi-hiroshima, Hiroshima 739-8526, Japan. E-mail: mabe@hiroshima-u.ac.jp

${ }^{b}$ JST-CREST, K's Gobancho, 7, Gobancho, Chiyoda-ku, Tokyo 102-0076, Japan

${ }^{c}$ Research Centre for Smart Materials, Hiroshima University, 1-3-1 Kagamiyama, Higashi-hiroshima, Hiroshima 739-8526, Japan

${ }^{d}$ IFMRI, National Institute of Advanced Industrial Science and Technology (AIST), 1-8-31 Midorigaoka, Ikeda, Osaka 563-8577, Japan. E-mail: k.kamada@aist.go.jp

${ }^{e}$ Centre for Instrumental Analysis, Niigata University, 8050 Ikarashi 2-no-cho, Nishi-ku, Niigata 950-2181, Japan

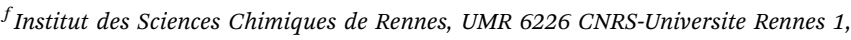
35042 Rennes, France. E-mail: claudine.katan@univ-rennes1.fr

${ }^{g}$ Laboratory of Structural Physiology, CDBIM, Graduate School of Medicine, The University of Tokyo, Bunkyo-ku, Tokyo 113-0033, Japan

${ }^{h}$ Advanced Ultrafast Laser Research Center, The University of Electro-Communications, Chofugaoka 1-5-1, Chofu, Tokyo 182-8585, Japan

$\dagger$ Electronic supplementary information (ESI) available: Experimental section, compound characterization and computational details. See DOI: 10.1039/ c5cc07664a
}

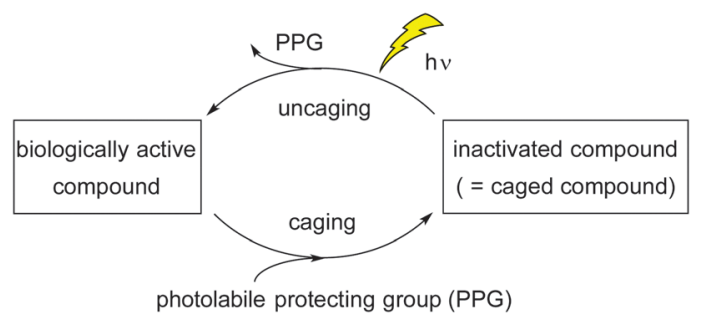

Fig. 1 Caging and uncaging of biologically active compounds upon photolysis.

have low absorption and scattering in this wavelength region. ${ }^{5,7}$ In addition, TPA enables spatially selective excitation of a small volume near the focal point of the laser beams. Thus twophoton (TP) excitation affords uncaging with higher spatial resolution, less photodamage to cells and tissues, and deeper penetration depth than one-photon (OP) excitation processes. ${ }^{5,7}$ However, to work under the physiological conditions, a high uncaging efficiency is required. This efficiency is defined as the uncaging quantum yield $\left(\phi_{\mathrm{u}}\right)$ multiplied by the excitation probability. ${ }^{8}$ The excitation probability can be expressed using the molar extinction coefficient $(\varepsilon)$ for OP excitation or using the TPA cross-section $\left(\sigma_{2}\right)$ for TP excitation. From this convention, TP-efficiency $\left(\delta_{\mathrm{u}}=\phi_{\mathrm{u}} \sigma_{2}\right)$ has the same units as the TPA cross section (GM). For biological applications, the minimum $\delta_{\mathrm{u}}$ threshold value currently accepted is 3 GM. ${ }^{9,10}$ This calls for development of biocompatible caged compounds with a sizeable $\delta_{\mathrm{u}}$ to ensure efficient release with tissue-permeable near-IR irradiation, providing valuable targets for applications in in vivo physiological studies.

Several PPGs with TPA character (TP-PPGs) have been reported so far. ${ }^{11,12}$ For instance, in 2006, Ellis-Davis and co-workers reported a nitrodibenzofuran (NDBF) skeleton with a planar biphenyl structure (Fig. 2). A caged calcium with the NDBF chromophore has a high $\varepsilon\left(18400 \mathrm{M}^{-1} \mathrm{~cm}^{-1}\right)$ and $\phi_{\mathrm{u}}(0.7)$ in the OP excitation process, ${ }^{12}$ but a low $\delta_{\mathrm{u}}(\sim 0.6 \mathrm{GM})$ in an aqueous buffer solution at $720 \mathrm{~nm}$ photolysis. Such a small $\delta_{\mathrm{u}}$ is not surprising, given that NDBF has a dipolar character with 


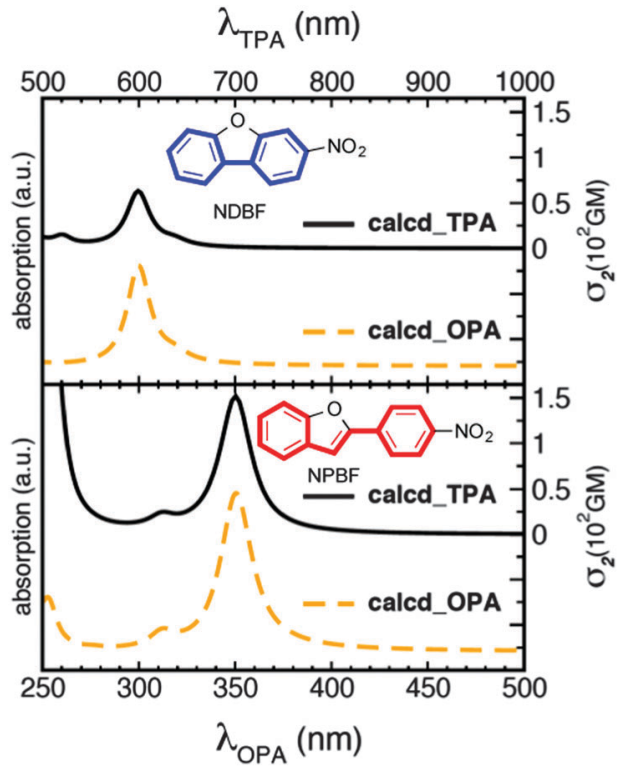

Fig. 2 Calculated OPA (dashed lines) and TPA (solid lines) spectra of NDBF (top panel) and NPBF chromophores (bottom panel).

an OPA maximum at $331 \mathrm{~nm},{ }^{13}$ that predicts the lowest energy TPA maximum near $660 \mathrm{~nm}$, far away from $720 \mathrm{~nm} .{ }^{14 a}$ This prompted us to design a new chromophore having a red-shifted absorption band.

The extension of the $\pi$-conjugation system is an efficient way to bathochromically shift the absorption maximum and also improve the TP properties of chromophores. ${ }^{15}$ At the same time, one may want to retain a simple synthetic scheme.

In our previous study, ${ }^{16}$ a stilbene skeleton was chosen for its inherently high TPA cross-section of $12 \mathrm{GM}$ at $514 \mathrm{~nm}$, in spite of its small $\pi$-conjugated portion. ${ }^{17,18}$ To avoid cis-trans isomerization in the excited state, the 1,2-dihydronaphthalene cyclic structure was chosen for the TP-uncaging reaction. ${ }^{16}$

We report herein the design and synthesis of a new TP-PPG with a 2-(4-nitrophenyl)benzofuran (NPBF) chromophore. The dipolar character of the donor- $\pi$-acceptor skeleton with a cyclic stilbene structure is promising to increase the TPA crosssection (Fig. 2). ${ }^{14,15}$ For comparison, the TP uncaging reaction of a caged benzoate 5 with NPBF is also investigated under irradiation in the $700-760 \mathrm{~nm}$ range.

First, the OPA and TPA spectra of the parent NPBF were computed at the TD-B3LYP/6-31G*//HF/6-31G* level of theory and compared with those of the NDBF core (Fig. 2). This level of theory has been shown to provide good predictions for structure-TPA relationships. ${ }^{14 a}$ A detailed discussion of the accuracy of the calculated TPA cross sections can be found in the ESI. $\dagger$ As expected, the extended $\pi$-conjugation system of the NPBF chromophore led to a sizable TPA cross-section of about $150 \mathrm{GM}$ at a longer wavelength of approximately $700 \mathrm{~nm}$ in gas phase. ${ }^{19}$ On the other hand, the NDBF chromophore showed a relatively small TPA cross-section of about $50 \mathrm{GM}$ at a shorter wavelength of about $600 \mathrm{~nm}$. The NPBF calculations prompted us to synthesize the caged benzoate $\mathbf{5}$ and investigate its TP photochemical reactivity. To compare the TP uncaging reaction
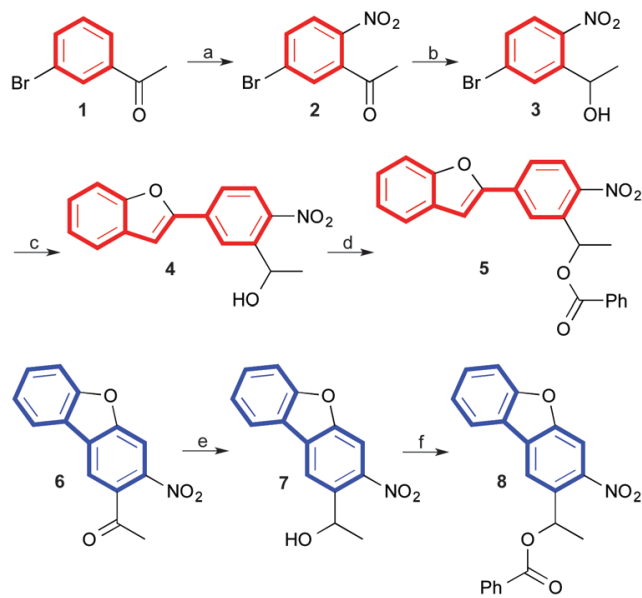

Scheme 1 Synthesis of 5 and 8. (a) $\mathrm{KNO}_{3}, \mathrm{H}_{2} \mathrm{SO}_{4}, 0{ }^{\circ} \mathrm{C}$ to $\mathrm{RT}, 2 \mathrm{~h}, 68 \%$. (b) $\mathrm{NaBH}_{4}, \mathrm{MeOH}, 0{ }^{\circ} \mathrm{C}$ to $\mathrm{RT}, 1 \mathrm{~h}, 95 \%$. (c) $\mathrm{Pd}\left(\mathrm{PPh}_{3}\right)_{4}, \mathrm{~K}_{2} \mathrm{CO}_{3}, 2$-benzofuranboronic acid, THF/water (1:1), $80{ }^{\circ} \mathrm{C}, 15 \mathrm{~h}, 95 \%$. (d) Benzoic acid, DCC, DMAP, $\mathrm{CH}_{2} \mathrm{Cl}_{2}, \mathrm{RT}, 16 \mathrm{~h}, 64 \%$. (e) $\mathrm{NaBH}_{4}, \mathrm{CH}_{2} \mathrm{Cl}_{2} / \mathrm{MeOH}(1: 1), 0{ }^{\circ} \mathrm{C}$ to $\mathrm{RT}, 1 \mathrm{~h}, 76 \%$. (f) Benzoic acid, DMAP, DCC, $\mathrm{CH}_{2} \mathrm{Cl}_{2}, \mathrm{RT}, 23 \mathrm{~h}, 56 \%$. THF = tetrahydrofuran, DMAP $=4$-dimethylaminopyridine, $\mathrm{DCC}=\mathrm{N}, \mathrm{N}^{\prime}$-dicyclohexylcarbodiimide.

of the NPBF chromophore with the NDBF chromophore, caged benzoate 8 was also prepared.

The syntheses of caged benzoates $\mathbf{5}$ and $\mathbf{8}$ are summarized in Scheme 1. The key intermediate 1-(5-bromo-2-nitrophenyl)ethane1-ol 3 was prepared using a modified method from our previous work, starting with 3-bromoaceto-phenone 1. ${ }^{16}$ Next, 1-(5-(benzofuran-2-yl)-2-nitrophenyl)ethane-1-ol 4, a compound exhibiting a rigid stilbene structure, was synthesized in 95\% yield by reacting 3 with commercially available 2-benzofuranboronic acid through a Suzuki-Miyaura cross-coupling. ${ }^{20}$ 1-(3-Nitrodibenzo[ $\left.b, d\right]$ furan-2-yl)ethane-1-one 6 was prepared according to a previously reported synthetic method, ${ }^{12}$ and was then rapidly reduced with $\mathrm{NaBH}_{4}$ to provide the corresponding alcohol 7, exhibiting a NDBF core. Finally, the benzoic acid (BA) moiety was introduced to alcohols $\mathbf{4}$ and 7 to provide the caged benzoates NPBF-BA $\mathbf{5}$ and NDBF-BA 8 in $64 \%$ and $56 \%$ yields, respectively. ${ }^{21}$

The absorption spectra of $\mathbf{5}$ and $\mathbf{8}$ were measured in DMSO (Fig. S14, ESI $\dagger$ ). The absorbance maxima of 5 and 8 were found at $364 \mathrm{~nm}\left(\varepsilon=12000 \mathrm{M}^{-1} \mathrm{~cm}^{-1}\right)$ and $320 \mathrm{~nm}\left(\varepsilon=9000 \mathrm{M}^{-1} \mathrm{~cm}^{-1}\right)$, respectively. The red shift and increased absorbance of 5 were found to be consistent with the theoretical predictions.

The photolytic release of carboxylic acid ${ }^{22}$ from compounds 5 and 8 was investigated by irradiation with a Xe-lamp at $360 \pm$ $10 \mathrm{~nm}$ in DMSO-d 6 (Fig. 3 and 4). The reaction was monitored using ${ }^{1} \mathrm{H}$ NMR (400 MHz). The NMR signals of benzoic acid in the aromatic region are shown in Fig. $3 \mathrm{e}$ and $4 \mathrm{e}$, with the overall time evolution of the reaction demonstrating a quantitative uncaging, larger than $90 \%$. The uncaging quantum yields $\phi_{\mathrm{u}}$ were determined in DMSO using the photochemical actinometer ferrioxalate coupled with high-performance liquid chromatography (HPLC), which led to values of 0.09 and 0.21 for 5 and 8 , respectively. Although the reported uncaging quantum yield of NDBF-EGTA $^{12}$ is 0.7 , that of the measured NDBF-BA species is 0.21 , despite having the same core. This indicates substituent 


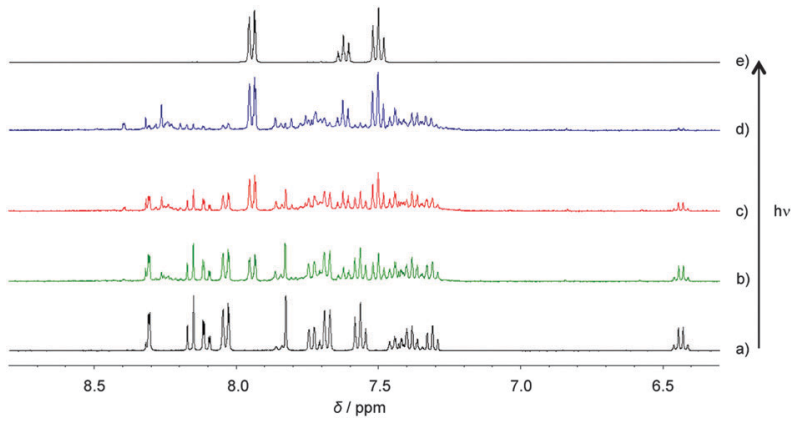

Fig. $3{ }^{1} \mathrm{H}$ NMR spectra of compound 5 in DMSO- $\mathrm{d}_{6}$ (a) before and after (b) 6, (c) 12, (d) and $24 \mathrm{~h}$ of irradiation at $360 \mathrm{~nm}$; (e) the ${ }^{1} \mathrm{H}$ NMR spectrum of benzoic acid in DMSO- $d_{6}$.

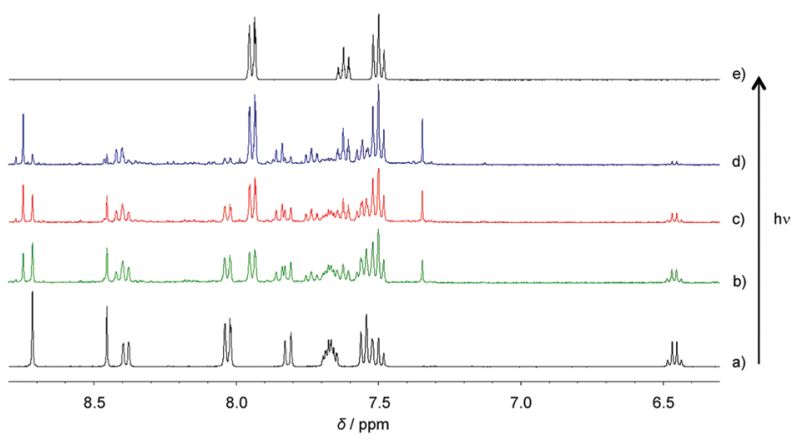

Fig. $4{ }^{1} \mathrm{H}$ NMR spectra of compound 8 in DMSO- $\mathrm{d}_{6}$ (a) before and after (b) 1, (c) 4, (d) and $6 \mathrm{~h}$ of irradiation at $360 \mathrm{~nm}$; (e) the ${ }^{1} \mathrm{H}$ NMR spectrum of benzoic acid in DMSO- $d_{6}$.

effects on the benzyl position of the $o$-nitrobenzyl caging groups. ${ }^{4}$ The OP photochemical efficiency $\left(\varepsilon_{360} \times \phi_{\mathrm{u}}\right)$ of the uncaging reaction of $5\left(\varepsilon_{360}=12000\right)$ at $360 \mathrm{~nm}$ was 1080 , which was nearly the same as the value of 1071 obtained for $8\left(\varepsilon_{360}=5100\right)$.

The TPA cross-sections of the parent cores of NPBF and NDBF were measured at $720 \mathrm{~nm}$ by the Z-scan method, in which the sample was moved along the path of the laser beam and the light intensity was measured by a detector as a function of its position on the $Z$-axis. ${ }^{23}$ Values of $18 \pm 3$ and $6 \pm 1 \mathrm{GM}$ were obtained for the NPBF and NDBF cores, respectively, at $720 \mathrm{~nm}$ in DMSO. Detailed information for the determination of the values can be found in the ESI. $\dagger$

TP photolysis of $\mathbf{5}$ and $\mathbf{8}$ was carried out in DMSO using 700 , 710, 720, 730, 740, 750, and $760 \mathrm{~nm}$ light from a Ti:sapphire laser (pulse width $100 \mathrm{fs}, 80 \mathrm{MHz}$ ) emitting at an average of $700 \mathrm{~mW}$. The consumption of $\mathbf{5}$ and $\mathbf{8}$ and the production of benzoic acid upon photolysis were monitored by HPLC (Fig. 5).

As shown in Fig. 5, the TP-uncaging rates were found to vary depending on the excitation wavelength. The fastest rate of $\mathbf{5}$ $\left(k_{740}=9.4 \times 10^{-6} \mathrm{~s}^{-1}\right)$ was found at $740 \mathrm{~nm}$ while that of 8 was at $700 \mathrm{~nm}\left(k_{700}=8.0 \times 10^{-6} \mathrm{~s}^{-1}\right)$. The data show the improved performance of the NPBF structure in $\mathbf{5}$ for the new chromophore. The other rate constants of TP uncaging reaction of $\mathbf{5}$ and $\mathbf{8}$ were measured in similar ways using near-IR photolyses (Fig. 5).

The rate constant of 5 at $720 \mathrm{~nm}$ was $3.1 \times 10^{-6} \mathrm{~s}^{-1}$ (Fig. 5a), about one third of the value that was observed at $740 \mathrm{~nm}$. Since the

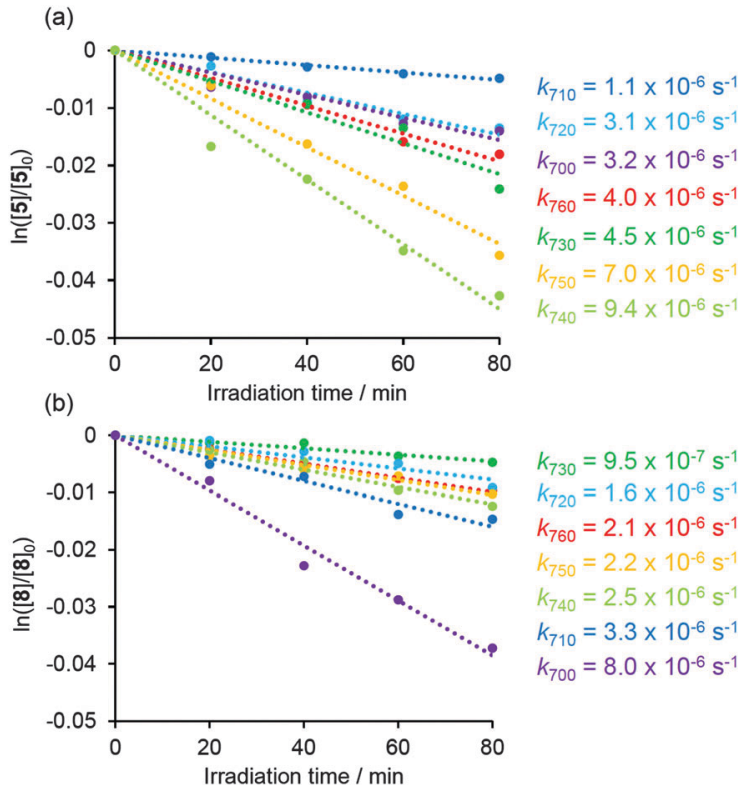

Fig. 5 Time profile of TP uncaging of (a) $\mathbf{5}$ and (b) $8, \ln$ ([sub]/[sub] $]_{0}$ ) versus irradiation time at wavelengths of $700,710,720,730,740,750$, and $760 \mathrm{~nm}$ and at a power of $700 \mathrm{~mW}$.

absolute value of the TPA cross-section of the NPBF core was $18 \mathrm{GM}$ at $720 \mathrm{~nm}$, the corresponding value at $740 \mathrm{~nm}$ can be extrapolated to be about $54 \mathrm{GM}$. This would give a $\delta_{\mathrm{u}}$ value of $5.0 \mathrm{GM}(54 \mathrm{GM} \times$ 0.09), which is higher than the threshold value of $\delta_{\mathrm{u}}>3 \mathrm{GM}^{9}{ }^{9,10}$

The TPA spectra of 5 and 8 over a wavelength range of $700-$ $760 \mathrm{~nm}$ were extrapolated based on the TPA cross-section values at $720 \mathrm{~nm}$ of the two species (Fig. 6). The new NPBF species clearly shows highly improved TPA in the near-IR region when compared to the previously reported NDBF derivatives.

The new TP-PPG-NPBF chromophore was successfully applied for the photochemical decomposition of ethylene glycol
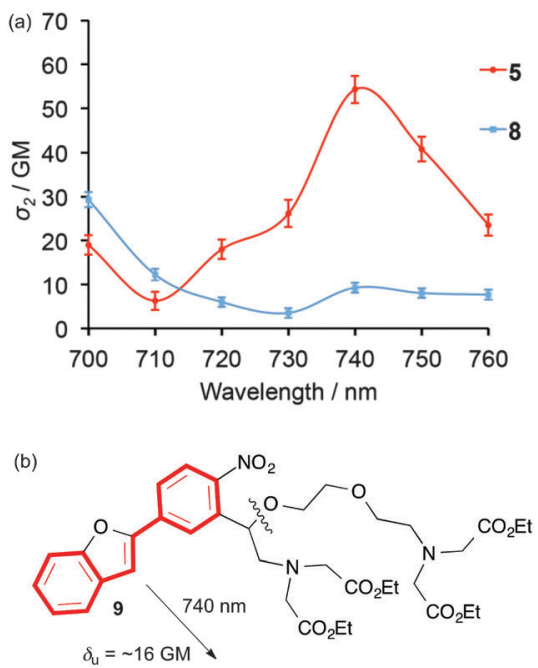

Fig. 6 (a) TPA spectra of $\mathbf{5}$ (red line) and $\mathbf{8}$ (blue line), as determined by the relative rate constants of the corresponding uncaging reactions; (b) TP reaction of 9 at $740 \mathrm{~nm}, \delta_{\mathrm{u}}=\sim 16 \mathrm{GM}, \phi_{\mathrm{u}}=0.3$. 
tetraacetic acid (EGTA) derivative NPBF-EGTA 9 (Fig. 6b). The EGTA unit is important for caging $\mathrm{Ca}^{2+} \cdot{ }^{12,24}$ The TP-induced fragmentation of the EGTA unit was observed with $\delta_{\mathrm{u}}=16 \mathrm{GM}$ $\left(\phi_{\mathrm{u}}=0.3\right)$ at $740 \mathrm{~nm}$ in benzene (Fig. S17 and S18, ESI $\dagger$ ).

In conclusion, a new NPBF chromophore with TPA capability was designed and synthesized. A simple increase in the $\pi$-conjugation length and donating ability led to a bathochromic shift and a significant increase in TP sensitivity. The OP photolysis of 5 showed the quantitative release of benzoic acid with a high uncaging efficiency $\varepsilon \phi_{\mathrm{u}}=1080$ at $360 \pm 10 \mathrm{~nm}$. Meanwhile, TP uncaging of 5 using near-IR light quantitatively produced benzoic acid with an efficiency of $5.0 \mathrm{GM}$ at $740 \mathrm{~nm}$, corresponding to a TPA cross-section of 54 GM. Furthermore, TP photolysis of 9 was found to induce the decomposition of the EGTA structure. This behaviour is superior to that of the NDBF derivatives, and makes it a promising TP-PPG, suggesting potential applications in physiology and neuroscience.

We thank N-BARD, Hiroshima University, for NMR and MS measurements. M. A. and K. K. gratefully acknowledge financial support from the Grant-in-Aid for Science Research on Innovative Areas "Stimuli-responsive Chemical Species" (No. 24109008 (MA); 25109544 (KK)) from the MEXT, Japan. C. K. acknowledges the HPC resources of CINES and of IDRIS under the allocations 2014-[x2014080649] made by GENCI (Grand Equipement National de Calcul Intensif).

\section{Notes and references}

1 (a) J. Engels and E.-J. Schlaeger, J. Med. Chem., 1977, 20, 907-911; (b) H. Kaplan, B. Forbush and J. F. Hoffmann, Biochemistry, 1978, 17, 1929-1935.

2 (a) W. J. McEntee and T. H. Crook, Psychopharmacology, 1993, 111, 391-401; (b) V. Parpura, T. A. Basarsky, F. Liu, K. Jeftinija, S. Jeftinija and P. G. Haydon, Nature, 1994, 369, 744-747.

3 (a) H. Mohler, Cell Tissue Res., 2006, 326, 505-516; (b) P. Somogyi and T. Klausberger, J. Physiol., 2005, 562, 9-26; (c) G. A. Ascoli, L. Alonso-Nanclares, S. A. Anderson, G. Barrionuevo, R. BenavidesPiccione, A. Burkhalter, G. Buzsaki, B. Cauli, J. DeFelipe, A. Fairen, D. Feldmeyer, G. Fishell, Y. Fregnac, T. F. Freund, D. Gardner, E. P. Gardner, J. H. Goldberg, M. Helmstaedter, S. Hestrin, F. Karube, Z. F. Kisvarday, B. Lambolez, D. A. Lewis, O. Marin, H. Markram, A. Munoz, A. Packer, C. C. H. Petersen, K. S. Rockland, J. Rossier, B. Rudy, P. Somogyi, J. F. Staiger, G. Tamas, A. M. Thomson, M. Toledo-Rodriguez, Y. Wang, D. C. West and R. Yuste, Nat. Rev. Neurosci., 2008, 9, 557-568.

4 (a) P. Klan, T. Solomek, C. G. Bochet, A. Blanc, R. Givens, M. Rubina, V. Popik, A. Kostikov and J. Wirz, Chem. Rev., 2013, 113, 119-191; (b) C. G. Bochet and A. Blanc, in Handbook of Synthetic Photochemistry, ed. A. Albini and M. Fagnoni, Wiley-VCH, Weinheim, 2010, pp. 417-447.

5 (a) C. Brieke, F. Rohrbach, A. Gottschalk, G. Mayer and A. Heckel, Angew. Chem., Int. Ed., 2012, 51, 8446-8476; (b) G. Bort, T. Gallavardin, D. Ogden and P. I. Dalko, Angew. Chem., Int. Ed., 2013, 52, 4526-4537; (c) H. M. Kim and B. R. Cho, Chem. Rev., 2015, 115, 5014-5055.

6 (a) J. A. Barltrop and P. Schofield, Tetrahedron Lett., 1962, 3, 697-699; (b) D. H. R. Barton, Y. L. Chow, A. Cox and G. W. Kirby, Tetrahedron Lett., 1962, 3, 1055-1057; (c) J. C. Sheehan and R. M. Wilson, J. Am. Chem. Soc., 1964, 86, 5277-5281; (d) J. A. Barltrop, P. J. Plant and P. Schofield, Chem. Commun., 1966, 822-823; (e) A. Patchornik, B. Amit and R. B. Woodward, J. Am. Chem. Soc., 1970, 92, 6333-6335.

7 (a) M. Matsuzaki, G. C. R. Ellis-Davis, T. Nemoto, Y. Miyashita, M. Iino and H. Kasai, Nat. Neurosci., 2001, 4, 1086-1092; (b) K. Svoboda and R. Yasuda, Neuron, 2006, 50, 823-839; (c) G. C. R. Ellis-Davies, Nat.
Methods, 2007, 4, 619-628; (d) A. Specht, F. Bolze, Z. Omran, J. F. Nicoud and M. Goeldner, HFSP J., 2009, 3, 255-264; (e) M. Pawlicki, H. A. Collins, R. G. Denning and H. L. Anderson, Angew. Chem., Int. Ed., 2009, 48, 3244-3266; $(f)$ D. Warther, S. Gug, A. Specht, F. Bolze, J. F. Nicoud, A. Mourot and M. Goeldner, Bioorg. Med. Chem., 2010, 18, 7753-7758; (g) G. C. R. Ellis-Davies, ACS Chem. Neurosci., 2011, 2, 185-197; (h) J. P. Olson, H. B. Kwon, K. T. Takasaki, C. Y. Q. Chiu, M. J. Higley, B. L. Sabatini and G. C. R. Ellis-Davies, J. Am. Chem. Soc., 2013, 135, 5954-5957; (i) J. M. Amatrudo, J. P. Olson, G. Lur, C. Q. Chiu, M. J. Higley and G. C. R. Ellis-Davies, ACS Chem. Neurosci., 2014, 5, 64-70.

8 TP uncaging efficiency $\left(\delta_{\mathrm{u}}\right)$ is expressed by the multiplication of a TPA cross-section $\left(\sigma_{\mathrm{u}}\right.$ in $\mathrm{GM}, 1 \mathrm{GM}=10^{-50} \mathrm{~cm}^{4} \mathrm{~s}$ per photon molecule) by the uncaging quantum yield $\phi_{\mathrm{u}}, \delta_{\mathrm{u}}=\sigma_{2} \times \phi_{\mathrm{u}}$. OP uncaging efficiency, $\varepsilon \times \phi_{\mathrm{u}}$, is expressed by the multiplication of an extinction coefficient $\varepsilon$ in $\mathrm{M}^{-1} \mathrm{~cm}^{-1}$ by the uncaging quantum yield $\phi_{\mathrm{u}}$.

9 Goeppert-Mayer (GM) unit: $1 \mathrm{GM}=10^{-50} \mathrm{~cm}^{4} \mathrm{~s}_{\text {photon }}{ }^{-1}$ molecule $^{-1}$; named in honor of Maria Goeppert-Mayer, who set the theoretical basis for the TPA process, see: M. Goeppert-Mayer, Ann. Phys., 1931, 401, 273-294.

10 N. I. Kiskin, R. Chillingworth, J. A. McCray, D. Piston and D. Ogden, Eur. Biophys. J., 2002, 30, 588-604.

11 (a) L. Donato, A. Mourot, C. M. Davenport, C. Herbivo, D. Warther, J. Leonard, F. Bolze, J. F. Nicoud, R. H. Kramer, M. Goeldner and A. Specht, Angew. Chem., Int. Ed., 2012, 51, 1840-1843; (b) A. Specht, F. Bolze, L. Donato, C. Herbivo, S. Charon, D. Warther, S. Gug, J. F. Nicoud and M. Goeldner, Photochem. Photobiol. Sci., 2012, 11, 578-586; $(c)$ C. Tran, T. Gallavardin, M. Petit, R. Slimi, H. Dhimane, M. Blanchard-Desce, F. C. Acher, D. Ogden and P. I. Dalko, Org. Lett., 2015, 17, 402-405; (d) H. J. Yin, B. C. Zhang, H. Z. Yu, L. Zhu, Y. Feng, M. Z. Zhu, Q. X. Guo and X. M. Meng, J. Org. Chem., 2015, 80, 4306-4312; (e) K. A. Korzycka, P. M. Bennett, E. J. Cueto-Diaz, G. Wicks, M. Drobizhev, M. Blanchard-Desce, A. Rebane and H. L. Anderson, Chem. Sci., 2015, 6, 2419-2426.

12 A. Momotake, N. Lindegger, E. Niggli, R. J. Barsotti and G. C. R. Ellis-Davies, Nat. Methods, 2006, 3, 35-40.

13 The absorption maximum of NDBF was observed at $331 \mathrm{~nm}$ $\left(\varepsilon=18945 \mathrm{M}^{-1} \mathrm{~cm}^{-1}\right)$ in DMSO, see the UV-vis spectrum of NDBF in the ESI $\dagger$ (Fig. S13a).

14 (a) F. Terenziani, C. Katan, E. Badaeva, S. Tretiak and M. BlanchardDesce, Adv. Mater., 2008, 20, 4641-4678; (b) H. M. Kim and B. R. Cho, Chem. Commun., 2009, 153-164; (c) S. Gug, F. Bolze, A. Specht, C. Bourgogne, M. Goeldner and J. F. Nicoud, Angew. Chem., Int. Ed,, 2008, 47, 9525-9529.

15 G. S. He, L. S. Tan, Q. Zheng and P. N. Prasad, Chem. Rev., 2008, 108, 1245-1330.

16 S. Boinapally, B. Huang, M. Abe, C. Katan, J. Noguchi, S. Watanabe, H. Kasai, B. Xue and T. Kobayashi, J. Org. Chem., 2014, 79, 7822-7830.

17 M. Albota, D. Beljonne, J. L. Bredas, J. E. Ehrlich, J. Y. Fu, A. A. Heikal, S. E. Hess, T. Kogej, M. D. Levin, S. R. Marder, D. McCordMaughon, J. W. Perry, H. Rockel, M. Rumi, C. Subramaniam, W. W. Webb, X. L. Wu and C. Xu, Science, 1998, 281, 1653-1656.

18 R. J. M. Anderson, G. R. Holtom and W. M. McClain, J. Chem. Phys., 1979, 70, 4310-4315.

19 The absorption maximum of NPBF was observed at $371 \mathrm{~nm}$ $\left(\varepsilon=23260 \mathrm{M}^{-1} \mathrm{~cm}^{-1}\right) \mathrm{nm}$ in DMSO, see the UV-vis spectrum of NPBF in the ESI $\dagger$ (Fig. S13b).

20 H. J. Lee, S. H. Kim, Y. R. Lee, X. Wang and W. S. Lyoo, Bull. Korean Chem. Soc., 2010, 31, 3027-3030.

21 A. K. Singh and P. K. Khade, Tetrahedron, 2005, 61, 10007-10012.

22 Photo-release of carboxylic acid derivatives, see: $(a)$ B. Amit and A. Patchornik, Tetrahedron Lett., 1973, 14, 2205-2208; (b) B. Amit, D. A. Ben-Efraim and A. Patchornik, J. Am. Chem. Soc., 1976, 98, 843-844; (c) J. Morrison, P. Wan, J. E. T. Corrie and G. Papageorgiou, Photochem. Photobiol. Sci., 2002, 1, 960-969; (d) A. D. Cohen, C. Helgen, C. G. Bochet and J. P. Tpscano, Org. Lett., 2005, 7, 2845-2848; (e) M. Matsuzaki, T. Hayama, H. Kasai and G. C. EllisDavies, Nat. Chem. Biol., 2010, 6, 255-257.

23 M. Sheik-Bahae, A. A. Said, T. H. Wei, D. J. Hagan and E. W. Van Stryland, IEEE J. Quantum Electron., 1990, 26, 760-769.

24 G. C. R. Ellis-Davies, Chem. Rev., 2008, 108, 1603-1613. 